\title{
Методика численного прогнозирования редкометалльных россыпей на основе формализации факторов россыпеобразования (на примере лопаритовых россыпей Ловозерского массива)
}

\section{Лаломов А.В., Бочнева А.А.}

Институт геологии рудных месторождений, петрографии, минералогии и геохимии РАН, Москва, lalomov@mail.ru

Аннотация. В пределах северной периферии Ловозерского массива (Кольский полуостров) выделены основные факторы формирования редкометалльных лопаритовых россыпей ближнего сноса. Произведена формализация (численная оценка) факторов; выработаны мультипликативные показатели, отражающие россыпной потенциал территорий; произведена оценка эффективности разработанных показателей на эталонных объектах северной периферии массива. Разрабатываемая методика позволяет автоматизировать процесс прогнозирования редкометалльной россыпной металлоносности.

Ключевые слова: редкометалльные россыпи, Ловозерский массив, прогнозное моделирование.

\section{Method of numerical forecasting of rare metal placers based on formalization of placer formation factors (on the example of loparite placers of the Lovozero massif)}

\section{Lalomov A.V., Bochneva A.A.}

Institute of Geology of Ore Deposits, Petrography, Mineralogy and Geochemistry of Russian Academy of Science, Moscow,lalomov@mail.ru

\begin{abstract}
Within the northern periphery of the Lovozero massif (Kola Peninsula), the main factors of the formation of rare-metal loparite placers of the near drift have been identified. The formalization (numerical assessment) of the factors is made. Multiplicative indicators reflecting the placer potential of the territories were developed. Assessment of the effectiveness of the developed indicators was made on the reference objects of the northern periphery of the massif. The developed methodology makes it possible to automate the process of forecasting of the rare metal placer parameters.
\end{abstract}

Key words: rare metal placers, Lovozero massif, predictive modeling.

Редкие металлы (в число которых входят и редкоземельные) являются основой развития современных инновационных технологий. Прогнозирование месторождений редких металлов возможно только на основе комплексного анализа всей совокупности факторов, объединенных в геолого-генетических моделях месторождений, использующих количественные оценки. В условиях нерентабельности экстенсивного развития промышленной базы необходима разработка новых технологий решений геологических задач. В число таких направлений входит «переход к передовым цифровым, интеллектуальным производственным технологиям, роботизированным системам, новым материалам и способам конструирования, создание систем обработки больших объемов данных, машинного обучения и искусственного интеллекта» (Указ .., 2016).

Для создания таких методик в области россыпей необходимо детально проанализировать данные по эволюции россыпеобразующих формаций в различных литогенетических, вещественных, геолого-структурных и литодинамически системах, конкретизировать, формализовать и ранжировать факторы россыпеобразования. На основе формализованных (количественно оцененных) факторов методами численного компьютерного моделирования и ГИС-технологий создается система пространственно привязанных мультипликативных показателей, оценивающих потенциал россыпной металлоносности. Полученные результаты используются для создания методики прогнозной оценки россыпной металлоносности на закрытых и малоисследованных территориях. В качестве объекта исследований для разработки моделей редкометалльных россыпей ближнего сноса были использованы россыпи лопарита северной периферии Ловозерского массива. 
Ловозерский массив, относящийся к позднедевонскому комплексу щелочных и нефелиновых сиенитов, вмещает несколько рудных горизонтов уртитов, содержащих промышленные концентрации лопарита, который представляет собой высококомплексное редкометалльное сырье, содержащее $\mathrm{Nb}_{2} \mathrm{O}_{5}-8.3 \%, \mathrm{Ta}_{2} \mathrm{O}_{5}-0.67, \mathrm{TiO}_{2}-39.8, \Sigma \mathrm{TR}_{2} \mathrm{O}_{3}-34.9$ (Когарко, 2002).

За счет эрозионных процессов на периферии массива образовались лопаритовые россыпи, промышленная значимость которых установлена по северной периферии плутона в пределах Ревдинского россыпного поля (Шомиокский и Сергеваньский участки). Местоположение россыпей контролируется участками максимального вскрытия лопаритоносных пород дифференцированного комплекса (ледниковыми карами и долинами, поставлявшими фрагментированный обломочный материал в зону предгорий) и элементами рельефа, благоприятными для накопления лопарита - локальными депрессиями коренного ложа (Лаломов и др., 2019).

При прогнозировании россыпей необходимо учитывать комплекс факторов, влияющих на металлоносность отложений - наличие коренных источников, динамические и литофациальные условия, геоморфологический контроль, тектонические условия и т.д. Только в условиях оптимальной совокупности таких факторов происходит образование россыпей, имеющих промышленное значение.

Сами по себе факторы россыпеобразования достаточно хорошо изучены (Шило, 2002; ПатыкКара, 2008), часть из них имеют количественную оценку, но большинство исследованы на качественном уровне. Авторами была поставлена задача компьютеризировать процесс прогнозирования россыпей (на данном этапе - редкометалльных россыпей ближнего сноса) на основе формализованных (количественно оцененных) факторов россыпеобразования.

Для этой цели для Ревдинского россыпного поля был выбран полигон моделирования, включающий эталонный (Шомиокский) и тестовый (Сергеваньский) участки (рис. 1). На участке $8 \times 11$ км, где были разведаны россыпи лопарита (Лихачев, 1984), по сети с элементарной ячейкой 500 м была собрана информация по россыпной металлоносности, рельефе, геоморфологии, мощности осадочного чехла, литолого-фациальным и стратиграфическим характеристикам осадочного чехла и кристаллического фундамента. Собранные данные были размещены в созданной на ГИС-основе базе данных.

Одним из наиболее значимых факторов контроля россыпной металлоносности является фациально-стратиграфический (ФС): россыпи приурочены в основном к верхнечетвертичным гляциальным отложениям местного горного оледенения и сопровождающих их флювиогляциальным комплексам.

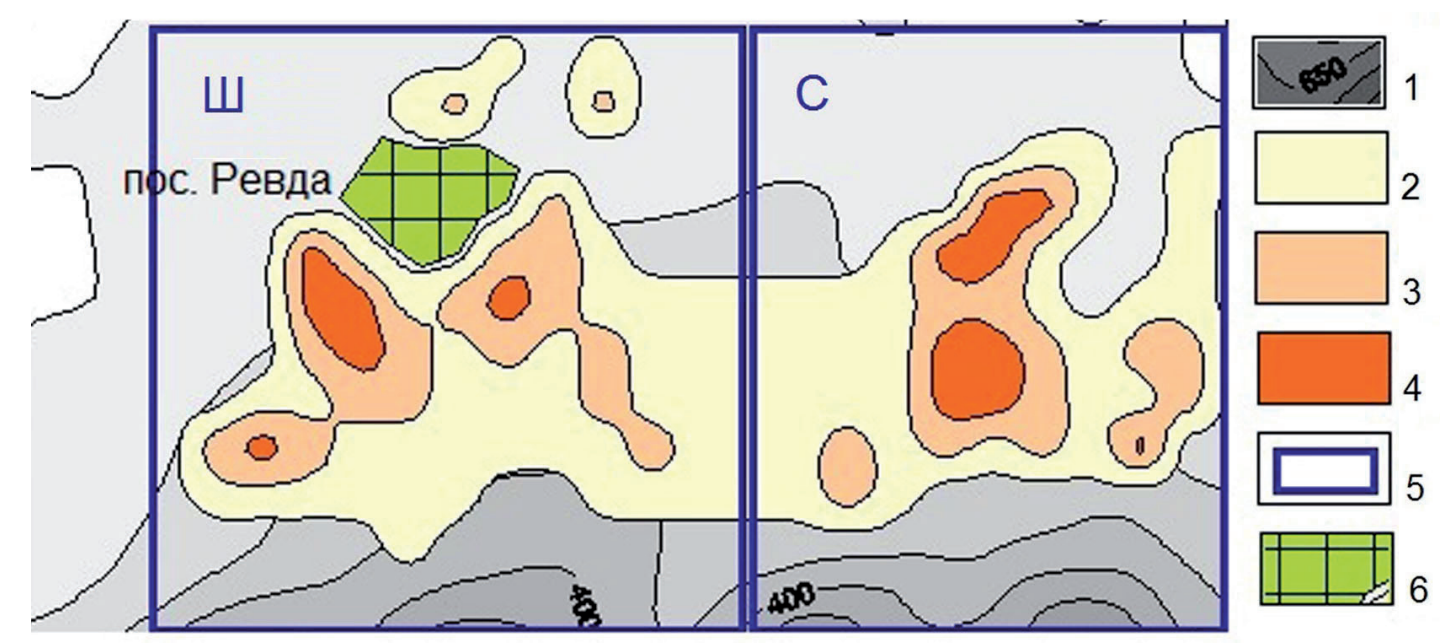

Рис. 1. Ревдинское россыпное поле и полигон моделирования.

1 - высотные отметки рельефа; 2-4 - содержания лопарита в россыпи (кг/м3): 2 - 2-4, 3 - 4-6, 4- более 6; 5 - границы участков: Ш - эталонный Шомиокский, С - тестовый Сергеваньский; 6 -населенный пункт (пос. Ревда).

Fig. 1. Revda placer field and modeling polygon.

1 - elevation marks of the relief; $2-4$ - content of loparite in the placer $(\mathrm{kg} / \mathrm{m} 3): 2-2-4,3-4-6,4-$ more than 6 ; 5 - boundaries of sites: $\amalg$ - reference Shomiok zone, C - test Sergevan zone; 6 - locality (Revda village). 
Мощность осадочного чехла (МЧ) закономерно уменьшается по мере удаления от приподнятой части массива, что непосредственно связано с тектоническим режимом блоков массива и фундамента. По этому параметру можно выделить 4 типа рыхлого чехла: (1) отсутствие чехла или маломощные грубообломочные элювиально-делювиальные отложения, приуроченные к приподнятой части и склонам массива; (2) делювиально-пролювиальный чехол мощностью до 5-10 м в периферийных зонах массива; (3) гетерогенный осадочный чехол мощностью до 10-30 м в экзоконтакте массива; (4) гетерогенный чехол мощностью более 30 м в пределах окружающей равнины. В целом концентрическое расположение этих зон нарушается дифференцированными смещениями отдельных блоков фундамента и массива, а также в результате эрозионной деятельности местного ледника, положение которого, в свою очередь, также определяется локальной тектоникой. Россыпи лопарита локализуются преимущественно, в третьей и второй зонах.

Важным фактором аллювиального россыпеобразования является динамические фазы аллювия, отражающие эрозионно-аккумулятивное состояние долин. Для формализации эрозионноаккумулятивного состояния (ЭАС) площадей авторами был разработан метод и рассчитан баланс материала для элементарной ячейки размером $500 \times 500$ м - сумма векторов приноса и выноса материала, пропорциональных разности высот с соседними ячейками. Для ячеек с преобладанием аккумуляции значения ЭАС положительные, эрозии - отрицательные.

Для учета геоморфологического фактора был применен показатель энергии рельефа (ЭР) (Спиридонов, 1985), рассчитываемый как разница, между максимальной и минимальной высотами в окружающих ячейках, деленная на высоту в центре ячейки.

ЭАС и ЭР рассчитываются на основе данных оцифрованного рельефа и являются независимыми от россыпной металлоносности. ФС и МЧ-фактор формализуются на эталонных участках, где имеются уже выявленные россыпи, их применение возможно только на объектах, аналогичных эталонному по геологическому строению и минеральному составу.

Формализация ФС и МЧ-фактора осуществлялась следующим образом: на эталонном объекте в каждой выделенной зоне с использованием данных разведочных работ (в нашем случае использован План изолиний содержаний лопарита Ревдинского россыпного месторождения (Лихачев, 1984) подсчитывается среднее содержание лопарита. Сумма средних содержаний по всем зонам нормируется на 1 , после чего рассчитывается коэффициент перспективности для каждой зоны, который присваивается каждой ячейке, попадающей в эту зону.

Для создания обобщенных прогнозных характеристик на данных эталонного объекта (Шомиокский участок) была построена матрица парных коэффициентов корреляции между выделенными факторами и содержаниями в россыпи лопарита (таблица). Факторы ФС, МЧ и ЭАС находятся в положительной корреляции с содержанием в россыпи лопарита, ЭР - в отрицательной.

Таблица. Коэффициенты корреляции (R) между содержаниями лопарита и формализованными показателями россыпной металлоносности для эталонного Шомиокского участка.

Table. Correlation coefficients $(\mathrm{R})$ between the grade of loparite and formalized indicators of the grade of placer metal for the reference Shomioks zone.

\begin{tabular}{|c|c|c|c|c|c|}
\hline \multirow{2}{*}{$\mathrm{T}$} & \multicolumn{4}{|c|}{ Факторы россыпеобразования } & \multirow{2}{*}{ МП } \\
\cline { 2 - 5 } & ФС & МЧ & ЭАС & ЭР & 0.57 \\
\hline
\end{tabular}

Примечание. МП эт $_{\text {р }}$ рассчитанный мультипликативный показатель для эталонного участка. Критическое значение $\mathrm{R}=0.18$ при объеме выборки $\mathrm{N}=184$ и доверительной вероятности $\alpha=0.99$.

В нашем случае МП для каждой элементарной ячейки і (MПі) по формуле (1) был рассчитан как произведение значений факторов для этой ячейки, имеющих положительную корреляцию с содержанием лопарита, деленное на значение фактора с отрицательной корреляцией:

$$
M \Pi_{i}=\left(\Phi C_{i} \times M \Psi_{i} \times Э A C_{i}\right) / Э P_{i}
$$


Коэффициент корреляции МП с содержанием лопарита на эталонном участке $(\mathrm{R}=0.57)$ является значимым для данной выборки (критическое значение $\mathrm{R}=0.18$ при объеме выборки $\mathrm{N}=184$ и доверительной вероятности $\alpha=0.99$ ), что позволяет использовать его в качестве критерия выделения площадей для поисков проявлений редкометалльных россыпей ближнего сноса.

Верификация предлагаемого алгоритма прогнозирования была проведена на тестовом Сергеваньском участке, для которого на ГИС-основе был рассчитан массив пространственно привязанных мультипликативных показателей (МП-тест).

Коэффициент корреляции рассчитанных значений МП-тест с содержаниями лопарита в россыпи, полученными по разведочным данным, R равен 0.55 (рис. 2). Это показывает возможность использования предлагаемой методики и расчетных мультипликативных показателей для прогнозирования редкометалльных россыпей ближнего сноса для постановки поисковых работ.

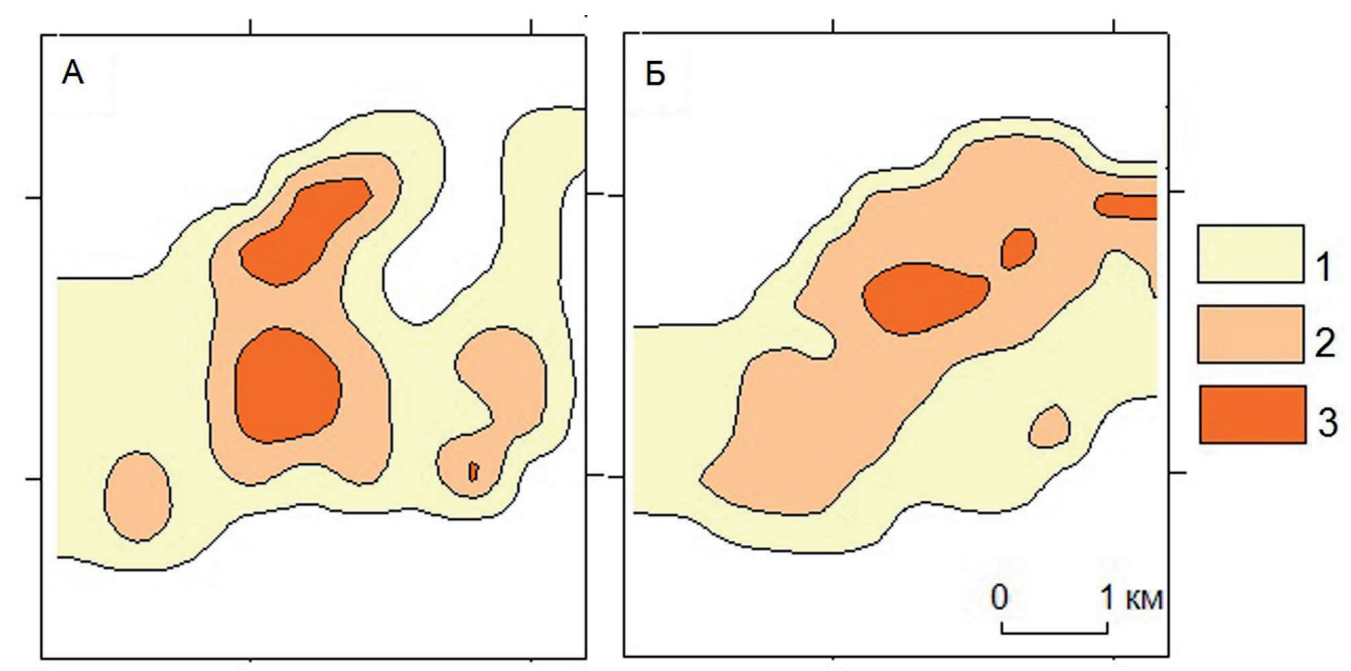

Рис. 2. Верификация методики прогнозирования редкометалльных россыпей на основе расчета мультипликативных показателей на Сергеваньском участке. А - содержания лопарита в россыпи по данным геологоразведочных работ; Б - расчетные значения по мультипликативным показателям. 1-3 - содержания лопарита в рос-

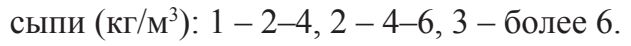

Fig. 2. Verification of the methodology for forecasting of rare metal placers based on the calculation of multiplicative indicators at the Sergevan zone. A - grade of loparite in placer according to geological exploration data; B - calculated values for multiplicative indicators. $1-3$ - grade of loparite in the placer $\left(\mathrm{kg} / \mathrm{m}^{3}\right): 1-2-4,2-4-6,3-$ more than 6 .

Разрабатываемая методика основана на анализе механизма принятия экспертом решений по оценке россыпного потенциала площадей и предлагает комплекс технологических решений, позволяющих имитировать когнитивные функции человека. Она даёт возможность с использованием гибридной системы, работающей в режиме диалога «оператор - компьютер», получать при выполнении конкретных задач результаты, сопоставимые с результатами интеллектуальной деятельности человека. Аналогичный подход уже используется для экспресс-оценки новых рудопроявлений золота в Арктической зоне России (Чижова и др., 2019).

Таким образом, на основе формализованных (количественно оцененных) факторов россыпеобразования, методами численного компьютерного моделирования и ГИС-технологий создана численная система расчета и позиционирования мультипликативных показателей, оценивающих потенциал россыпной редкометалльной металлоносности.

На «полигоне моделирования» с уже известными месторождениями и россыпепроявлениями в пределах «эталонной» выборки данных формализованные показатели выделяются и оцифровываются, верифицируются на «тестовой» выборке, и в случае подтверждения ее адекватности система может быть использована для прогнозирования россыпного потенциала на площадях, сходных по 
геолого-структурным и металлогеническим характеристикам с полигоном моделирования. Метод получил подтверждение на участке Сергеваньский.

Создаваемая система позволяет собирать, хранить, обрабатывать и визуализировать данные на всех этапах процесса создания прогнозных оценок. Система не требует специализированных данных и использует данные стандартных геологических отчетов и картографические материалы. Применение методики основано на стандартных алгоритмах и не стребует от оператора высокой квалификации и обширного геологического опыта.

Работы проведены в рамках государственного задания по программе № 0136-2019-0006.

\section{Литература}

1. Когарко Л.Н. Проблемы генезиса гигантских редкометалльных месторождений Кольского полуострова / Российская Арктика: геологическая история, минерагения, экология. СПб. Изд-во: ВНИИОкеангеология. 2002. С. 773-787.

2. Лаломов А.В., Григорьева А.В., Бочнева А.А., Магазина Л.О., Чефранов Р.М, Редкометалльные россыпи Ловозерского массива // Разведка и охрана недр. 2019. № 1. С. 51-56.

3. Лаломов А.В., Чефранов Р.М. Разработка метода прогнозирования потенциала россыпей на основе формализации факторов россыпеобразования на базе лопаритовых россыпей Ловозерского массива // Арктика: экология и экономика. 2020. № 4 (40). C. 54-65. DOI: 10.25283/2223-4594-2020-4-54-65.

4. Лихачев А.С. Геологическая записка к ТЭО и расчету временных кондиций по Ревдинскому россыпному месторождению. ПГО Севзапгеология, Мурманская ГРЭ. Апатиты. 1984. (фондовая, № ТФГИ № 3226).

5. Патык-Кара Н.Г. Минерагения россыпей: типы россыпных провинций. М.: ИГЕМ РАН, 2008. 528 с.

6. Спиридонов А.И., Геоморфологическое картирование. М. Изд-во: Недра. 1985. 184 с.

7. Указ Президента Российской Федерации от 01.12.2016 г. № 642 «О Стратегии научно-технологического развития Российской Федерации» [Электронный ресурс]. 2016. http://www.kremlin.ru/acts/bank/41449 (дата обращения 08.02.2021).

8. Чижова И.А., Лобанов К.В., Волков А.В. Логико-информационные модели для прогноза и оценки новых месторождений золота в Арктической зоне России // Арктика: экология и экономика. 2019. № 4 (36). C. 107-117. DOI: 10.25283/2223-4594-2019-4-107-117.

9. Шило Н.А. Учение о россыпях. Владивосток. Изд-во: Дальнаука. 2002. 576 с. 